\title{
La información especializada en internet: directorio de recursos de interés académico y profesional (Ángeles Maldonado y Luis Rodríguez-Yunta, coords.)
}

\author{
Por Amadeu Pons
}

Amadeu Pons. "La información especializada en internet: directorio de recursos de interés académico y profesional (Ángeles Maldonado y Luis Rodríguez-Yunta, coords.)". Reseña de libro. En: El profesional de la información, 2007, mayo-junio, v. 16, n. 3, pp. 273-274.

DOI: 10.3145/epi.2007.may.14

Maldonado-
Martínez, Ángeles;
Rodríguez-Yunta, Luis
(coords.). La información
especializada en Internet:
directorio de recursos
de interés académico
y profesional. $2^{\underline{a}}$ ed.,
correg. y aum. Madrid:
Consejo Superior de
Investigaciones Científicas,
Centro de Información y
Documentación Científica,
2006. 495 p., 1 CD.
ISBN $84-00-08436-5$.
$28 €+$ IVA.

LOS MÁS VIEJOS del lugar recordarán con nostalgia los repertorios clásicos de fuentes de información elaborados por Malclès y Sabor... A los no tan viejos les sonarán los nombres de Sheehy (o Balay) y Walford ${ }^{1}$.

A estos nombres de bibliógrafos hay que añadir un par de apellidos desde hace unos años: Maldonado y Rodríguez-Yunta, coordinadores de la obra objeto de nuestro comentario en su nueva edición ${ }^{2}$. Se trata, como sus predecesores, de un repertorio selectivo de fuentes de información útiles para especialistas, profesionales y demás interesados en cualquier ámbito del conocimiento. Como bien indica el título, todas las fuentes seleccionadas se encuentran en línea.

\section{Estructura y autores}

La obra está estructurada en 15 capítulos, cada uno de los cuales está firmado por un experto en la materia: «1. Herramientas de localización de recursos de información en Internet» (Ángeles Maldonado, Cindoc), «2. Páginas de bibliotecas y OPAC» (Isabel Mendoza, CSIC), «3. Bases de datos bibliográficas» (Luis Rodríguez-Yunta, Cindoc); «4. Distribuidores de bases de datos» (Ceferina Anta, Cindoc); «5. Revistas electrónicas» (Elea Giménez-Toledo, Cindoc); «6. Plataformas de acceso a publicaciones electrónicas» (Elena Primo-Peña, Instituto de Salud Carlos III); «7. Fuentes en Internet para el estudio del acceso abierto a la literatura científica» (José-Manuel Barrueco, Universitat de València); «8. Obras de referencia: enciclopedias, diccionarios, glosarios y otros recursos del idioma» (Sylvia Fernández, Cindoc); «9. Portales y comunidades virtuales de información especializada en Internet» (Isabel Fernández-Morales y Sonia JiménezHidalgo, Cindoc); «10. Periodismo digital: medios de comunicación en Internet» (Víctor-Manuel Pareja, Cindoc); «11. Recursos multimedia en Internet» (Isabel FernándezMorales y Sonia Jiménez-Hidalgo, Cindoc); «12. Documentación jurídica en Internet» (Julio Macías, Universidad Carlos III); «13. Fuentes primarias: la documentación archivística en Internet» (Francisco Fernández-Izquierdo, CSIC); «14. Recursos de interés sobre informá-

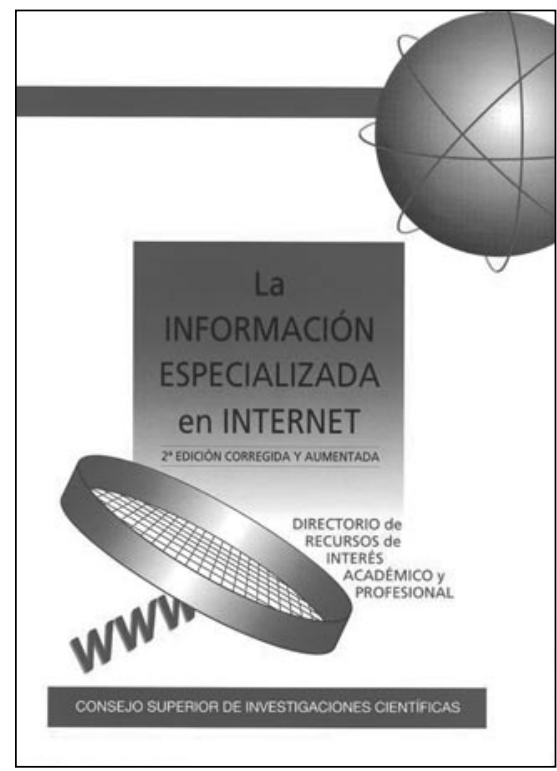

tica, tecnologías de la información y software» (Carlos Tejada, Universidad Complutense de Madrid); «15. Recursos de información sobre el sistema español de I+D» (Isabel Fernández, Sonia Jiménez y Javier Salvador, Cindoc).

Cada capítulo empieza con una breve introducción al tema de que trata: en ocasiones se presentan las características y tipología del material objeto de estudio, otras veces se da una aproximación sistemática al tipo de información de la que posteriormente se dan las fuentes principales. De manera que este repertorio no sólo ofrece una cuidada selección de recursos en línea de calidad, sino que permite adquirir conocimientos estructurados sobre nuevos tipos de fuentes de información, estrategias de búsqueda... Entre otras, destacaré por su calidad las explicaciones preliminares de los capítulos pri- 
mero («Herramientas de localización de recursos de información en Internet»), tercero («Bases de datos bibliográficas») y duodécimo («Documentación jurídica en Internet»).

\section{Fuentes de información}

Después de la presentación teórica nos encontramos con lo sustancial de cada capítulo: la selección de recursos. En el conjunto del libro se mencionan unas 2.100 fuentes, a una media de 140 por capítulo (aunque nos encontramos con un par que no llegan a 20 y un par que superan los 300). La mayoría de los recursos seleccionados vienen acompañados por un breve comentario, en general de carácter analítico, que no ocupa generalmente más de 100 palabras. A lo largo del texto hay numerosas reproducciones de pantallas (en blanco y negro) que amenizan la lectura. Al final de la mayoría de capítulos se ofrece una selección bibliográfica de textos que permiten al lector ampliar sus conocimientos -interesante especialmente para la formación de los futuros profesionales de la información-.

La obra tiene un alcance geográfico internacional, y recoge recursos en distintas lenguas -predominando el inglés, como es lógico-. Pero se da prioridad, cuando ello es posible, a fuentes en español (también algunas representativas en catalán). Este es otro de sus méritos importantes. Al final de la obra se incluye un índice alfabético de materias.

El libro se acompaña de un CD donde encontramos recogidos todos los enlaces citados en el libro (solamente los enlaces, no así los comentarios ni las introducciones teóricas a los capítulos) y que nos permite acceder cómodamente a las fuentes. El CD sigue la misma estructura que la obra impresa, y no permite la localización rápida de un determinado recurso si no sabemos en qué capítulo se encuentra (podemos suplir la falta de un buscador interno con las opciones de búsqueda de Windows).
Algunas direcciones que quedaron obsoletas en el papel se han actualizado en el CD.

A pesar de que la selección de recursos es muy fiable y recoge las mejores fuentes en cada área temática, podríamos señalar algunos olvidos, cosa casi inevitable con la cantidad de información manejada. Por ejemplo, en el capítulo 2 no se encuentran el Directorio de bibliotecas españolas (el más completo de su género, elaborado por la Biblioteca Nacional:

http://www.bne.es/cgi-bin/ wsirtex $? F O R=W B N D I B I 4$

el catálogo colectivo de Francia:

http://ccfr.bnf.fr/

o WorldCat:

http://www.worldcat.org/

En el capítulo 5 podría haberse citado el portal del ISSN y en el 8 añadiría los traductores automáticos Translendium:

\section{http://www.translendium.com}

Pero estos olvidos y otros pequeños errores, inevitables insisto, no deben oscurecer la imagen general de la obra, brillante herramienta, muy adecuada para enfrentarse al conocimiento de las mejores fuentes de información especializada.

\section{Obsolescencia}

Un inconveniente no achacable a los responsables de la obra es la paulatina desactualización de algunas URL. Este hecho es más de lamentar si se da en sitios web de organismos oficiales, que deberían cuidar la persistencia de las direcciones, como por ejemplo ha sucedido recientemente con el Ministerio de Cultura español.

Otra laguna inevitable, debida a la evolución de los tiempos. Hay que contar que la fecha de los últimos contenidos incorporados corresponde a la segunda mitad de 2005. Por ello no aparecen en esta obra algunas referencias surgidas recientemente. Por ejemplo, YouTube. De la mis- ma manera, se citan en más de un apartado los buenísimos repertorios Sosig y Humbul, hoy convertidos en Intute. Pero esto no debe ser entendido como un demérito de la obra: ¡es inevitable el vertiginoso paso del tiempo!

\section{Sugerencias para la tercera edición}

Para finalizar, un par de sugerencias para mejorar la recuperación de la información: incorporar un índice alfabético de los títulos seleccionados -tanto en la versión impresa como en la electrónica- para ayudar a localizarlos sin tener que pensar primero en qué capítulo pueden estar incluidos. Otro detalle sin más transcendencia: que en el encabezamiento de las páginas figure el título del capítulo donde nos encontramos (no solo el título de la obra, como consta ahora). Esto ayuda a ubicar al lector y a localizar el dato buscado.

El lector ya se hará cargo de que estos pequeños detalles no empañan el gran mérito de esta obra, sin parangón en la cultura hispánica. Repertorio imprescindible en la mesa de trabajo de cualquier persona que precise recuperar de manera habitual información de calidad de la red, y también como bibliografía de apoyo para los estudiantes universitarios. Excelente.

\section{Notas}

1. Las dos primeras, ya no actualizadas: LouiseNoëlle Malclès, Manuel de bibliographie, 4e éd. rev. et augm. (Paris: Presses universitaires de France, 1985) y Josefa E. Sabor, Manual de fuentes de información, $3^{\mathrm{a}}$ ed., corr. y aum. (Buenos Aires: Marymar, 1979). Las dos últimas, plenamente vigentes: Robert Balay (ed.). Guide to reference books, 11th ed. (Chicago [etc.]: American Library Association, 1996) y Ray Lester (ed.). The new Walford: guide to reference resources. London: Facet Publishing, 2005-.

2. Esta segunda edición representa un incremento de información de más del $50 \%$ respecto de la primera, publicada a finales de 2001 .

Amadeu Pons, Facultat de Biblioteconomia i Documentació, Universitat de Barcelona

pons@ub.edu 